\title{
Analyses on the Preference Scale of Inbound Tourist Market in Yi Chang City
}

\author{
Xiaohui Shao ${ }^{\mathrm{a},}{ }^{*}$, Chun Liub \\ School of Management, Wuhan Industry and Business University, Wuhan 430065, China \\ azijian1206@qq.com, blc576@126.com
}

Keywords: The preference scale, Inbound tourist market, Yi Chang city.

\begin{abstract}
Inbound tourism market is an important part of the tourism market, the analysis on inbound tourism market is conducive to improve the competitiveness of tourism destination. Based on the relevant statistical data of 2001-2012 in Yichang inbound tourism market, the paper analyzes the changes of Yichang inbound foreign tourist market, reveals the overseas tourists' destination preference degree of Yichang. According to the analysis result, it puts forward different countermeasures to the different tourist source, aims to maintain the vitality market for Yichang city.
\end{abstract}

\section{Introduction}

Inbound tourism is an indispensable part of international tourism, and a country or region's Tourism strength can be measured by the number of inbound tourists and foreign currency incomes from tourism ${ }^{[1]}$. Inbound tourists, due to their different social nature, economy condition, ideology, life style, education level, age, occupation, etc. they show their preferences in choosing a travel destination. Researches on inbound tourists' preference are contributing to a good understanding of inbound tourists' destination's preference, and to learn the structure of the tourism market characteristics, development potential and the dynamic trend of better targeted groups.According to the market demands and development of tourism products, and the dynamic changes of the tourist market, we can improve the efficiency of the tourist destination promotion work and target well, continuously expand and consolidate the overseas tourist market ${ }^{[2]}$.

\section{The Background and Significance of the Research}

According to "Several Opinions of the State Council on Promoting the Reform and Development of the Tourism Industry" pointed out that tourism destinations should vigorously develop the inbound tourism market. It points the way for Yichang --to enhance the reform and development of the inbound tourism market.

Implementation Opinions of Hubei province People's Government on Promoting the Reform and Development of the Tourism Industry points to promote the development of tourism industry reform, expand opening to the outside world with carrying out international direct flights between major tourist cities, grasping the stopover 72 hours visa-free policy, improving service efficiency and service level, aims on improving the satisfaction of tourists to increase the selectivity of visitors.

According to tourism statistical bulletin, in 2013 Yichang has received 343400 inbound tourists, the foreign exchange reaches $\$ 82.731$ million, year-on-year growth of $4.4 \%, 4.4 \%$ respectively, which reveals that the number of inbound tourists each year to Yichang has been in constant growth. Meanwhile, it also reveals that the inbound tourism accounts for the proportion of the whole tourism market is not big and quality of inbound tourism is not high, how to display the advantages to the best of Yichang City tourism has become an important issue of economic development.

Based on the analysis on the preference scale by the quantitative analysis of the overseas tourist market in Yichang City, this paper clears the sources of the market share and market growth rates, summarizes the development trend and development potential of each source country, puts forward the Countermeasures for Yichang to explore the targeted development of inbound tourist market, 
provides a scientific direction of practice. It aims on helping with developing the Yichang Tourism Industry successfully, to attracting the reforming of other similar tourism destinations in the central of China, to building a new tourism economic circle. It tries to make some contribution to the central tourism and economic development.

\section{The Present Situation of the Inbound Tourism Market in Yichang}

In the past 30 years, Yichang has obtained the rapid development of economy, at the same time, the continuous increase in the number of inbound tourism, inbound tourism source markets are also gradually improve. From The interannual variation of inbound tourists and exchange revenue (2001-2012) in Yichang as figure 1, Yichang inbound tourism market presents a high speed development trend. But in 2003, the impact of SARS events on the development of China's tourism market is huge, and Yichang is no exception, So we take 2003 as the time node, the Yichang inbound tourism development is divided into two stages: 2003-2009 is a stable stage of development, the number of inbound tourists from 2003 in 101743 to 2009 in 174885, tourist foreign exchange income also increased from $\$ 21.085$ million to $\$ 36.6478$ million; 2009-2012 for the rapid rising stage, received a surge in the number of inbound tourists from 174885 until 329004, the foreign exchange income also rapidly increased from $\$ 36.6478$ million to $\$ 70.5394$ million.

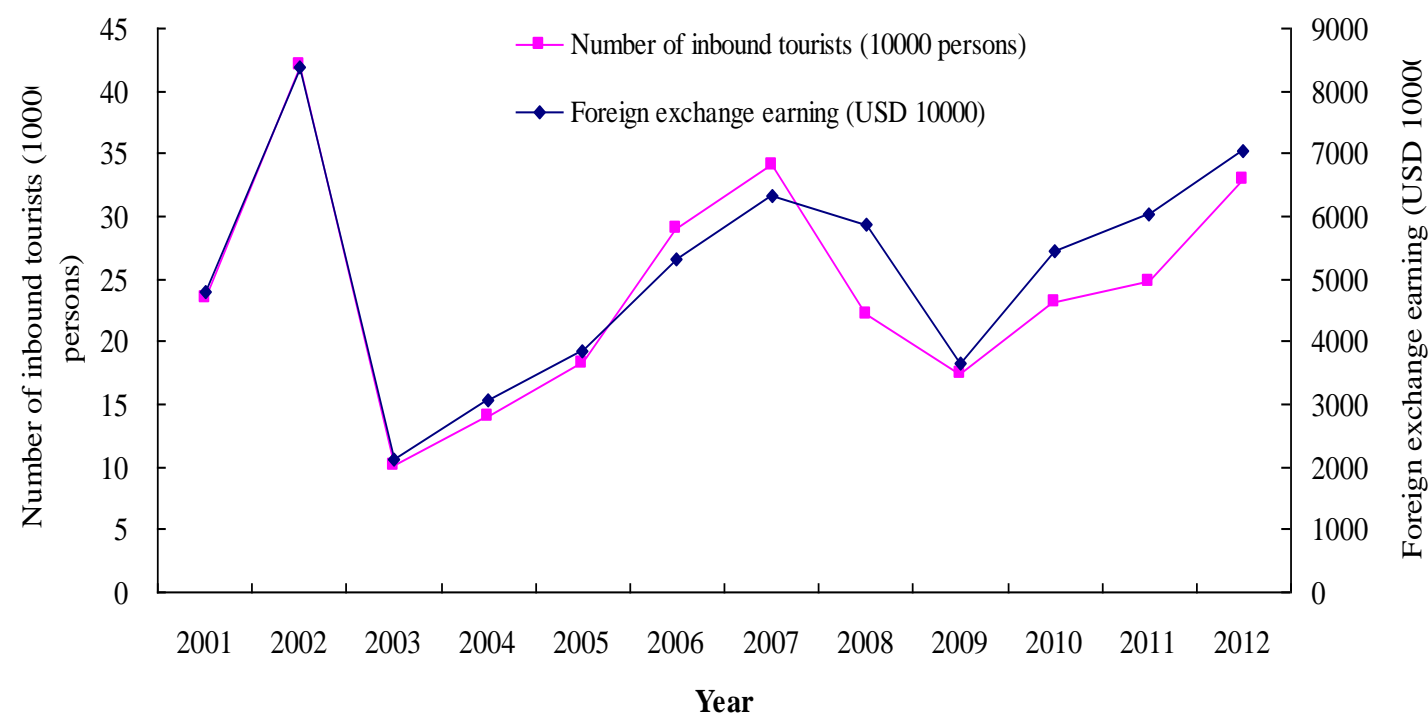

Fig. 1 The Interannual Variation of Inbound Tourists and Exchange Revenue (2001-2012)inYichang

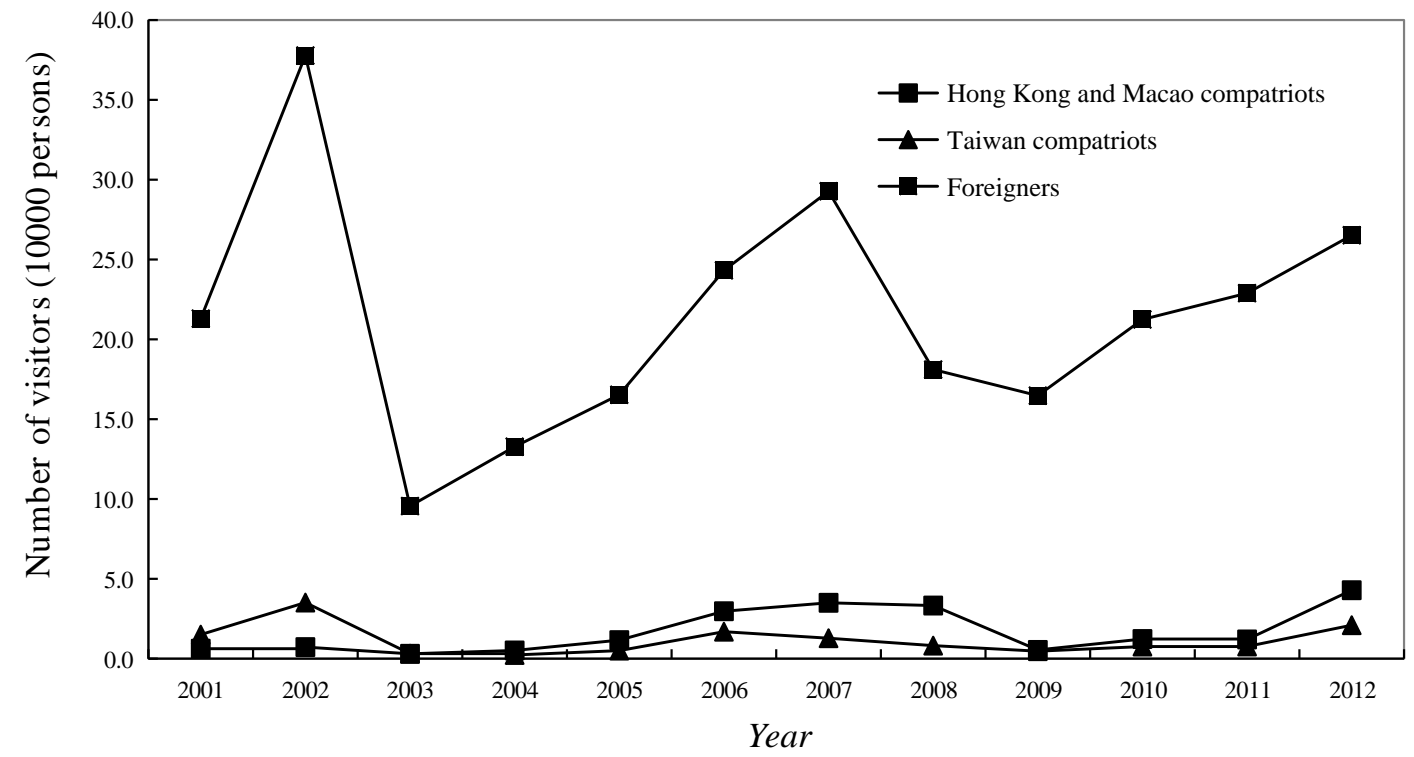

Fig. 2 Passenger volume change of inbound tourists in Yichang City (2001-2012) 
According to China's tourism statistics, the composition of the inbound tourism source markets generally divided into Hong Kong and Macao compatriots, the Taiwan compatriots and foreigners. The figure 2 shows the foreign market is the main part of Yichang inbound tourism market. In 2003, for the time node, due to the effect of SARS, Yichang share of the inbound tourism market is starting to decline. After 2003, Hong Kong and Macao compatriots' market tourism market dropped from $10.09 \%$ in 2002 to $5.30 \%$ in 2004, showing a downturn, but the proportion of foreigners soared. The impact of the financial crisis, Hong Kong and Macao compatriots accounted for Yichang's inbound tourist market share dropped to $5.8 \%$, foreigners share in the inbound tourism market in the lowest $81.38 \%$ in 2008. Although this proportion is as high as $94.2 \%$ in 2009 , later the development tends to be gentle. From 2001 to 2012, in the 12 years, foreigners in Yichang city tourism market accounted for an average of $89.16 \%$ of the total inbound tourism market, with the increasing number of foreign tourists, inbound tourism market in Yichang, foreigners have become the main source of the inbound tourism market.

\section{Analysis on inbound Tourists' Market in Yichang Based on the Preference Scale}

\subsection{The preference scale model}

The preference scale model, is used to study the degree of tourism preference of the international tourist market to a domestic tourist destination, focusing on visitors to the destination choice [3].From the following formula can be seen in the mathematical meaning of preference scale is a tourist visitors at the destination of the market share and its total number of tourists to China tourism in the national market share ratio, such a substantial percentage of what we would call a preference index.

Preference scale model formula expressed as:

$$
P \quad=\frac{S D / F D}{S C / F C}
$$

In the formula: $\mathrm{P}=$ Preference scale; $\mathrm{SD}=$ the number of tourists from a certain country in the destination $; \mathrm{FD}=$ the number of inbound tourists in the destination $; \mathrm{SC}=$ the number of inbound tourists in $\mathrm{China} ; \mathrm{FC}=$ The number of inbound tourist arrivals in China.

According to the preference degree, inbound tourist markets can be divided into: preference tourist market $(\mathrm{P} \geq 1)$, the sparse scenery tourist market $(0 \leq \mathrm{P}<1)$; according to the preference and the sparse scenery degree of preference will further subdivide the preference tourist market as strong $(2 \leq \mathrm{P}<\infty)$, weak Pro scenery tourist market $(1 \leq \mathrm{P}<2)$, weak non preference market $(0.5 \leq \mathrm{P}<1)$ and strong non preference market $(0 \leq \mathrm{P}<0.5)^{[4]}$.

But this model has the characteristics of location entropy, Due to the tourists' travel condition is not clear, the model is built on the basis of the tourists, visitors to China without considering the proportion of its total number of trips, so the preference scale model has certain relativity, the size and the number of degrees of tourist landscape not positively related to the preference scale and the number of tourists are not necessarily related, it reflects the choice of tourist behavior, preference of tourist to tourism destination. From the perspective of market competition, the preference degree reflects the market competitiveness of the tourist market, a preference scale is larger, the tourism destination in the national market in the market more competitive; on the other hand, the preference scale is smaller, weaker competitiveness ${ }^{[5]}$.

Due to the existence of defects, so when the theory is used in the domestic tourism market, there is a certain one sidedness, the analysis also should be combined with the actual number of tourist visitors.

\subsection{Survey on the Preference Scale of Inbound Tourists' Market of Yichang City}

According to Yichang Statistical Yearbook, published tourism statistics, Yichang inbound tourist markets including Asia (South Korea, Thailand, Japan, Singapore); the European market (Britain, Germany, France, Italy, Switzerland, the United States, Canada); Oceania (Australia, New Zealand) etc. The database is derived from the statistical data in 2001-2012. The preference scale model of different source market in the preference scale (Figure 3), In view of the one year's landscape value 
can not reflect the classification of Yichang inbound tourist market, and the preference scale has been constantly changing, so this survey took the 2001-2012 average value of preference scale (Table 1), the Yichang inbound tourism market analysis, draw the following conclusions:

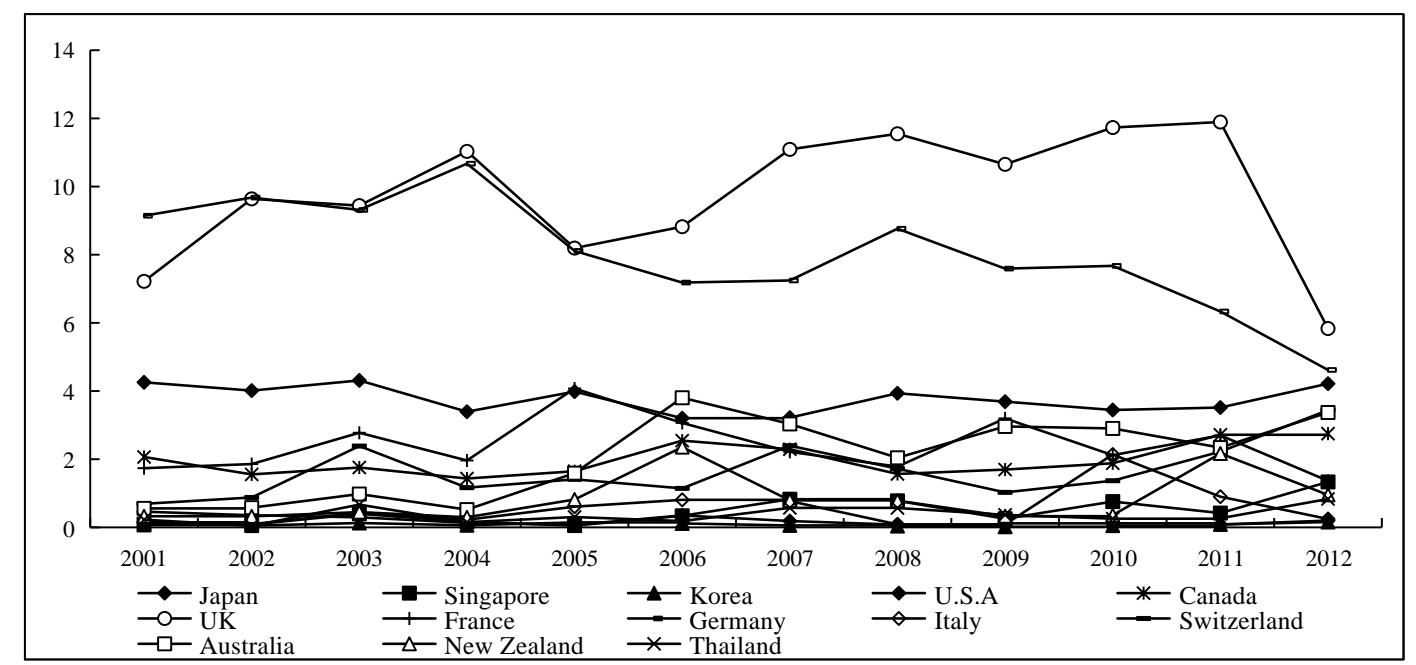

Fig 3 the graph of interannual variation about Preference Scale of inbound Tourists' Market in Yichang from 2001 to 2012

Table 1 The Average Preference Scale of Inbound Tourists Market in Yichang (2001-2012)

\begin{tabular}{|c|c|c|c|c|c|c|c|c|c|c|c|c|c|}
\hline Years & Japan & Singapore & $\begin{array}{l}\text { South } \\
\text { Korea }\end{array}$ & US & Canada & British & French & Germany & Italy & Swiss & Australia & $\begin{array}{c}\text { New } \\
\text { Zealand }\end{array}$ & Thailand \\
\hline 2001 & 0.461 & 0.1 & 0.071 & 4.256 & 2.065 & 7.219 & 1.737 & 9.144 & 0.149 & 0.691 & 0.557 & 0.326 & 0.226 \\
\hline 2002 & 0.356 & 0.082 & 0.052 & 4.013 & 1.554 & 9.639 & 1.858 & 9.676 & 0.094 & 0.878 & 0.578 & 0.323 & 0.046 \\
\hline 2003 & 0.295 & 0.398 & 0.128 & 4.312 & 1.757 & 9.441 & 2.776 & 9.315 & 0.431 & 2.386 & 0.978 & 0.448 & 0.668 \\
\hline 2004 & 0.133 & 0.164 & 0.062 & 3.394 & 1.433 & 11.032 & 1.963 & 10.672 & 0.224 & 1.165 & 0.521 & 0.296 & 0.151 \\
\hline 2005 & 0.073 & 0.053 & 0.146 & 3.984 & 1.648 & 8.195 & 4.075 & 8.112 & 0.607 & 1.409 & 1.591 & 0.818 & 0.304 \\
\hline 2006 & 0.351 & 0.34 & 0.115 & 3.204 & 2.545 & 8.822 & 3.064 & 7.183 & 0.808 & 1.144 & 3.803 & 2.355 & 0.185 \\
\hline 2007 & 0.186 & 0.827 & 0.057 & 3.22 & 2.293 & 11.091 & 2.216 & 7.244 & 0.771 & 2.396 & 3.035 & 0.792 & 0.572 \\
\hline 2008 & 0.08 & 0.779 & 0.038 & 3.935 & 1.567 & 11.549 & 1.784 & 8.763 & 0.088 & 1.722 & 2.041 & 0.784 & 0.569 \\
\hline 2009 & 0.118 & 0.254 & 0.018 & 3.689 & 1.696 & 10.652 & 3.197 & 7.592 & 0.088 & 1.027 & 2.962 & 0.329 & 0.367 \\
\hline 2010 & 0.119 & 0.757 & 0.051 & 3.444 & 1.881 & 11.732 & 2.119 & 7.673 & 2.138 & 1.369 & 2.903 & 0.358 & 0.255 \\
\hline 2011 & 0.083 & 0.42 & 0.086 & 3.516 & 2.717 & 11.894 & 2.7 & 6.335 & 0.9 & 2.222 & 2.34 & 2.168 & 0.267 \\
\hline 2012 & 0.199 & 1.333 & 0.157 & 4.216 & 2.75 & 5.834 & 1.366 & 4.619 & 0.247 & 3.439 & 3.371 & 0.954 & 0.833 \\
\hline AVG & 0.205 & 0.459 & 0.082 & 3.765 & 1.992 & 9.758 & 2.405 & 8.027 & 0.545 & 1.654 & 2.057 & 0.829 & 0.37 \\
\hline
\end{tabular}

\section{1) The preference scale significant difference}

As shown in figure 3, The preference scale of inbound tourist market in Yichang from 2001 to 2012 difference obvious, volatile ups and downs is bigger, the preference scale higher prevalence in recent years. The biggest preference scale is 11.894 (the UK, 2011), a minimum is 0.018 (South Korea, 2009). Just 2012 analysis, kiss scene degree is one of the biggest for the British (5.834), South Korea (0.157) is minimum. On the 2012 annual analysis, the largest preference scale belongs the United Kingdom (5.834), the smallest for South Korea (0.157).We can Classify of the Preference Scale of inbound tourist market in Yichang as table 2. 
Table 2 Classify of the Preference Scale of inbound tourist market in Yichang (2012)

\begin{tabular}{|c|c|}
\hline preference scale & tourist market \\
\hline Strong preference tourist market $(2 \leq P<\infty)$ & $\begin{array}{c}\text { Germany, France, Britain, the United States, } \\
\text { Australia }\end{array}$ \\
\hline The weak preference tourist market $(1 \leq P<2)$ & Canada, Switzerland \\
\hline Weak non preference market $(0.5 \leq P<1)$ & Italy, New Zealand \\
\hline $\begin{array}{c}\text { strong non preference tourist market } \\
(0 \leq P<0.5)\end{array}$ & South Korea, Thailand, Japan, Singapore \\
\hline
\end{tabular}

\section{2) The overall degree of the Preference Scale of inbound tourist market ups and downs in Yichang}

Yichang inbound tourism market preference shock is relatively small, and more frequent, the preference degree is not stable, but obviously can see, from the beginning of 2008, the highest degree of preference in Britain and Germany began to decline, although subsequently rebounded slightly, but the trend can not be changed, but the original preference degree is low the country has a small increase, the future trend of the preference degree is not very clear.

The Preference Scale degree of inbound tourism market in Yichang is divided into two trends change, one is a country with a high degree of the Preference Scale, the Preference Scale is volatile, while the countries with lower Preference Scale relatively stable, but both of them have been within his own shocks.

3) The Reasons for the change of the Preference Scale in Yichang inbound tourist market

a) In addition to the Three Gorges is the famous tourist attractions in Yichang, there is no internationally renowned tourist destination, so a single tourism resources is also an important factor restricting the development of inbound tourism in Yichang.

b) By the "SARS", the financial crisis and other unexpected factors, foreign tourists to China's choice will be unstable, which directly affects the situation of inbound tourism in Yichang. Of course, positive energy activities such as World Expo can have a positive impact on the landscape.

c) The world's economic environment is also affecting the inbound tourism in Yichang.

d) The implementation of the strategy of the rise of the central region of China has brought new opportunities for the economic development of Yichang.

e) In recent years, Hubei province in the world to do a variety of countries to promote the promotion of tourism, as the representative of the scenic spots of the Three Gorges scenic spots in Hubei province has become an indispensable propaganda.

\section{Conclusion}

According to analysis on the preference scale of inbound tourist market in Yichang City, it shows that the ways of developing Yichang inbound tourism:

First, to consolidate the European market, with America, Britain and Germany such a high market share of the country, the Three Gorges of the Yangtze River has been unable to meet the needs of tourists, we should actively explore some ecological tourism, adventure tourism and wellness tourism point and attract more tourists to Yichang tourism, allowing visitors to stay days increasing.

Secondly, focus on the depth of excavation for the Asian market, near the China of South Korea, Japan and Singapore, Thailand, outbound tourism in small radius and the preference degree is not high, the market share and the growth rate is not an ideal situation, the government should strengthen the promotion, in accordance with the requirements of market segmentation, the theme of propaganda for life;

Thirdly, to Oceania country with better living environment, improve infrastructure, optimize the environment of tourism may be a good idea at the moment. 


\section{Acknowledgments}

This work was financially supported by Hubei province tourism development committee 2015 Annual Research Project(2015006)\& Wuhan Industry and Business University Annual Research project(A2013005)fund.

Corresponding author: Xiaohui Shao, School of Management, Wuhan Technology and Business University, Wuhan 430065, CHINA

\section{References}

[1] Yin Min. Inbound tourism market present situation and development countermeasures of Jiangxi province ,J, Journal of social science in Jiangxi Province, 2005, (8): 12-15

[2] Ma Yao-feng, Liang Wang-bing. Based on the close view of the brigade of China market research - in six major tourist hotspot cities in our country, for example, J, Journal of travel, 2005, (1): 126-128.

[3] Liu Zhi-xing, Ma yao-feng. The entry of foreign tourist market of Inner Mongolia analysis, J, Journal of arid zone resources and environment, 2014, 28 (1): 35 to 37.

[4] Liu Su-heng. Inbound tourism tourist market of hubei province kiss scene degrees [J]. Journal of business review, 2009, (11), 187.

[5] Wang De-gen. Spatial and temporal variation characteristics of suzhou international tourism source markets research, J, Journal of geography and geographic information science, 2006, (2): 15. 